\title{
UNA BREVE HISTORIA MUSICAL DE Ciudad JuÁrez ${ }^{1}$
}

\author{
A brief MUsical history of Ciudad JuARez
}

SERVANDO PINEDA JAIMES ${ }^{2}$

\section{RESUMEN}

1 1 texto tiene como objetivo realizar un breve repaso por la historia musical de Ciudad Juárez de los siglos XX al XXI. Es un acercamiento a la reconstrucción de esta línea del tiempo por el que ha transitado la música en la frontera, desde los tiempos previos a la Revolución, pasando por la Ley Seca en los EE.UU., que se tradujo aquí en las big bands, hasta el rock and roll, la música latinoamericana, los narco-corridos, hasta el rap, el hip hop y más reciente, el auge de las orquestas sinfónicas.

1 Una versión resumida de este texto se publicó con el título: Breve aproximación a la historia de la música en Ciudad Juárez, en el libro: Patrimonio Cultural Musical de Chihuahua, publicado por la Facultad de Artes de la Universidad Autónoma de Chihuahua y la Secretaría de Cultura del Gobierno del estado de Chihuahua en 2018. Agradezco la ayuda de Luis Maguregui, músico e investigador musical de Ciudad Juárez y actual director del Centro Municipal de las Artes del Instituto para la Cultura del municipio de Juárez (IPACULT), por sus valiosos comentarios que permitieron mejorar este texto; así como a Mónica Sarahí Rodríguez del Programa de Licenciatura en Sociología de la Universidad Autónoma de Ciudad Juárez, quien auxilió en la transcripción de entrevistas y ordenamiento del material aquí utilizados. Extiendo mi agradecimiento a Marisela Ortiz Rivera por sus comentarios puntuales a este escrito. Sobra decir que los errores y omisiones son responsabilidad única del autor.

2 Universidad Autónoma de Ciudad Juárez. Correo: spineda@uacj.mx 
Palabras clave: Música, historia, Ciudad Juárez, grandes bandas, frontera.

\begin{abstract}
This article aims to briefly review the musical history of Ciudad Juarez of the 20th and 21st century. The approach reconstructs the timeline of musi'sc traves and evolution along the border, from before the Revolution, through Prohibition in the United States, which translated locally into the so-called Big Band,Rock and Roll, Latin American music, Narcocorridos, and into Rap, Hip-Hop, and most recently, the boom of Symphonic Orchestras.
\end{abstract}

Key words: music, history, Ciudad Juarez, big bands, border.

Desde sus inicios, Ciudad Juárez fue una ciudad musical. Si en alguna parte del vasto territorio nacional se ha vivido por y para la música, es en esta urbe fronteriza. El juarense visionario y emprendedor, volteó a el turismo y convirtió la diversión y la música en negocio. A partir de entonces, aquí todo se dijo y se hizo con música. Historia musical de Ciudad Juárez. Grupo de Facebook

\title{
INTRODUCCIÓN
}

Cuando las luces se apagan, al tiempo que se ilumina el majestuoso escenario, se corren las cortinas y aparece una espectacular banda, que al ritmo de Glenn Miller, abre la noche. La noche apenas inicia y los ritmos de jazz, foxtrot, tango y swing retumban por todos los rincones de la mítica avenida Juárez. Luces de neón, espectaculares bandas, bailarines, cómicos, cantantes, y sobre todo, grandes músicos que hacen de Juárez la "Ciudad del pecado" 
que cubre una época maravillosa en la historia de la música en la frontera norte de México.

Años atrás, una bucólica Ciudad Juárez de apenas menos de 10 mil habitantes, comenzaba a vibrar con los temas afrancesados de los valses, los favoritos de los mexicanos, y se preparaba para ser protagonista de una de las épocas más espectaculares que nuestro país recuerde. Una bella época que dio paso al nacimiento de majestuosas bandas, espectaculares músicos y maravillosos cantantes, tanto hombres como mujeres.

Tratar de reconstruir la historia de la música en Ciudad Juárez, resulta una tarea más que portentosa. Una a una, cada época se traslapa con la otra. Solo una línea muy delgada las separa. No obstante, y nada más con fines de estructuración del presente texto, podemos identificar claramente cinco diferentes épocas que marcaron las noches de la frontera. Debido a las limitaciones de espacio, no se realiza aquí una exhaustiva y detallada cronología, sino solo una pincelada de lo que se vivió y gestó en cada una de ellas, con sus principales aportes, excesos y ausencias que las marcaron.

En este sentido, la época de los grandes casinos, lujosos restaurantes y espectaculares cabarets, van de la mano con las majestuosas bandas, toda una pléyade de cantantes -hombres y mujeres-, y músicos que dieran lustre a aquellas interminables noches de pecado, donde la lujuria y el buen vino, la buena música y los grandes espectáculos hicieron de esta frontera la referencia obligada en el país. El punto para triunfar. El punto para ser conocido. El punto para que nacieran innumerables estrellas.

No obstante, hay serias dificultades para documentar estos momentos de la historia. Trabajos que den cuenta de la llamada época del esplendor en esta frontera existen, pero están enfocados a ese ambiente de fiesta perenne, de los excesos y de las rutilantes estrellas que pasaron por Ciudad Juárez. Sin embargo, desde el punto de vista de la musicología, los trabajos son escasos y se tiene que hacer una verdadera labor de gambusino musical en busca de pepitas de oro que den una orientación real sobre lo que 
pasó en cada una de las épocas que se vivieron en Ciudad Juárez durante el siglo XX y principios del XXI.

Este es un acercamiento a la reconstrucción de esta línea del tiempo por el que ha transitado la música en la frontera, pasando por la época previa al esplendor musical, que tuvo su gran impulso cuando Estados Unidos aprobó en enero de 1920 la Ley Volstead, mejor conocida como la Ley Seca, que prohibía de manera absoluta la producción, venta y consumo de bebidas alcohólicas en todo el país, lo que se tradujo que en México decenas de centros nocturnos, salones de bailes, cantinas, casinos y restaurantes tuvieran un rutilante nacimiento.

En cosa de un par de décadas pasamos de los bucólicos valses, mazurcas y polkas vienesas que se tocaban por todo lo ancho y largo del país, a los estridentes pasos del swing, el foxtrot, el jazz y por supuesto las llamadas big bands o grandes bandas que marcaron toda una época en la que luego sería llamada como la "Ciudad del pecado", la "Sodoma y Gomorra del Norte".

Luego vendría el boom maquilador y con ello, el comienzo del fin de aquellas épocas de esplendor, de lujo y buen gusto y de los restaurantes de postín, los autos relucientes con sus impecables choferes al volante, para dar paso al no menos espectacular y loco rock and roll, que dio origen a impactantes grupos que dieron fama a esta frontera. A los años locos, vendría un breve periodo que en los hechos se convierte en una verdadera contracultura: la música latinoamericana, la cual tuvo también su breve repunte en este lugar, en contraposición a la cultura dominante estadounidense. Eran los tiempos del latinoamericanismo, como una forma de oponerse al avasallante poder del vecino del norte, que imponía sin rubor el consumo cultural en el mundo, con su música, sus bailes, su cine y su literatura.

Ya a lo lejos y solo como un breve y fugaz recuerdo de aquellos tiempos idos, a la par de los procesos democratizadores que comenzaban a vivirse en nuestro país, aparece una forma de música que hacía recordar los escenarios violentos de la Revolución mexicana, solo que al caballo de los corridos revolucionarios, ahora se le sustituía por la flamante troca y a las carabinas 30-30 de 
nuestros ancestros, las pavorosas AK-47. Son los narcocorridos, la música de los tiempos violentos del narcotráfico. ${ }^{3}$

Luego vendrá la cumbia y la banda -no las grandes bandas-, hasta llegar a un intenso movimiento musical en la frontera donde cobran su carta de naturalización el rap, el hip-hop, la música tecno, heavy y sus diferentes combinaciones, hasta un inédito auge de orquestas sinfónicas como nunca antes se había visto en la frontera. ¿Qué sigue?

Luis Maguregui, músico y uno de los principales investigadores, que como gambusino, trata de rescatar la historia de nuestra música, lo condensa con una frase que le atribuye a don Carlos Chávez, creador de la Sinfonía India y de la Orquesta Sinfónica Nacional:

[... yo espero que haya lugar para que se desarrolle una música propia y también para que se cultive la gran música. Porque no nada más es hacer música propia, también es que la gente la conozca. Mira hay una frase que me gusta mucho, de don Carlos Chávez. Carlos Chávez, el compositor mexicano de la Sinfonía India, fundador de la primera Sinfónica Nacional y fundador del INBA, del Instituto Nacional de Bellas Artes. Don Carlos Chávez decía: al pueblo no hay que darle lo que pide, al pueblo hay que enseñarle a pedir (Maguregui, 2017).

Y su apuesta la coloca en las nuevas generaciones de músicos y cantantes que se forman hoy, lo mismo en las aulas de la Licenciatura en Música de la Universidad Autónoma de Ciudad Juárez y en las del Centro Municipal de las Artes, del Instituto para la Cultura del municipio de Juárez, y de muchas otras tantas escuelas donde se imparte música, una música que pretende dar un nuevo rostro a Ciudad Juárez.

3 Luis Maguregui, músico y actual director del Centro Municipal de las Artes del Instituto para la Cultura de municipio de Juárez [Entrevista realizada el 28 de noviembre de 2017]. 


\section{LA VOCACIÓN MUSICAL DE CIUDAD JUÁREZ}

Los diferentes periodos por los que ha pasado la historia musical de Ciudad Juárez se han hecho con profusión en crónicas periodísticas principalmente, pero también por medio de la historia oral, con las dificultades que ello representa debido a la ausencia de materiales escritos o sonoros que nos permitan saber a ciencia cierta cómo ocurrieron los hechos. Sin embargo, prácticamente no hay habitante en la frontera mayor de sesenta años que no tenga alguna historia que contar sobre aquellos años maravillosos y locos de las grandes bandas, del jazz, del swing, del foxtrot y los grandes casinos, cabarets y restaurantes, pero escasean trabajos que intenten ordenar cronológicamente la historia de la música en la frontera. En ese sentido hay dos textos con profusión de información respecto a lo que sucedió en cada una de estas épocas, pero no guardan un orden cronológico, por lo que es difícil hacer un rastreo de los músicos y cantantes de cada una de estas épocas. Se trata de los libros del periodista Emilio Gutiérrez de Alba: Tívoli. Bailando con la Historia, publicado por ediciones del Azar AC en 2002 y La Fiesta. Recuerdos de una alegre y luminosa Ciudad Juárez del siglo XX, publicado por la Universidad Autónoma de Ciudad Juárez en 2011. El primer texto se trata de una interesante recopilación de la vida nocturna de Ciudad Juárez. Hace un minucioso relato de la música que se cantó, se tocó y se bailó en la frontera en la época de los grandes cabarets, las grandes bandas y maravillosos cantantes. En el segundo, detalla la vida de uno de los centros nocturnos más importantes de la vida del espectáculo en la ciudad.

Un trabajo prácticamente fundacional en torno a la vida musical y nocturna de Ciudad Juárez, es el de Jaime Castañeda, Estrellas de la Noche, publicado en 1996 por la Universidad Autónoma de Ciudad Juárez, a través del Fondo para la Modernización de la Educación Superior, Programa de Investigación para la Extensión, Vinculación y la Cultura. Prácticamente no hay texto que aborde el tema de los años locos de Ciudad Juárez que no haga referencia al trabajo de Castañeda. 
Lidia Sandoval y Leticia Peña, abordan estos tiempos desde el punto de vista de la identidad cultural y el desarrollo urbano. Así queda de manifiesto en su trabajo: Historia del cabaret y vida nocturna como transformadores de la identidad cultural en el centro de Ciudad Juárez, Chihuahua, México, donde describen desde un concepto histórico, el proceso de los años dorados del cabaret, su pertinencia, permanencia y ocaso, además de la influencia que tuvieron en el contexto urbano.

Por su parte, Elvira Maycotte y Ramón Leopoldo Moreno (2010), en su trabajo Entre el temor y la inseguridad, la creación de una zona de silencio en la actividad turística de Ciudad Juárez, exponen la situación que se vive en Ciudad Juárez, desde el punto de vista turístico, y el peligro que significa visitar ciertos lugares como el centro de la ciudad:

[...] la generación en ella de una zona del silencio producto de la disminución de tareas y prácticas relacionadas con ella identificando aquellos sitios que tuvieron un desarrollo amplio en las décadas anteriores a los 2000 y que hoy en 2010, se convierten en centros o en vías de extinción a consecuencia de las crisis estadounidenses y de la inseguridad que se ha asentado a partir del 2006 en la ciudad.

Otros autores como Gabriel Rayos García, se ocupan de los tiempos recientes. En su trabajo: La Heroica [sic] Ciudad Juárez, cuatro elementos identitarios: La frontera, la maquila, los centros o plazas comerciales y lo norteño, publicado en 2014, Rayos García centra su análisis en aquellos íconos que nos dan identidad como juarenses.

En ese sentido, no hay claridad sobre los periodos en que deben dividirse y estudiar la historia de la música en esta frontera. Sin embargo, hay un relativo consenso, sobre algunas etapas, ya que es muy marcada su influencia y productos surgidos de cada uno de ellos. Sin más ánimo que tratar de estructurar el presente texto, podemos identificar las siguientes: 
1. Periodo romántico. Podemos ubicarlo a fines del siglo XIX y hasta la primera década del siglo XX, por el tipo de música que se tocaba: valses, polkas.

2. Periodo de la Ley Seca y la Guerra. Se ubica de 1920 y se extiende hasta la década de los años 70.

3. Periodo de la maquila y el rock and roll. Inicia con el boom maquilador y se prolonga hasta los años 80.

4. Periodo de la liberación y el latinoamericanismo. El auge de la contracultura a la hegemonía estadounidense; abarca los años 70 a los 90.

5. La nueva ola fronteriza. Es la época que abarca del 2000 hasta la actualidad, con diversas modalidades y tipos de música.

Debe aclararse que la periodización propuesta es totalmente arbitraria y ciertamente puede haber otras tantas. El objetivo únicamente es ordenar la narración de cada una de estas épocas, describir muy someramente lo que ocurrió en cada una; dejamos para historiadores y expertos el tratar de establecer una correcta periodización de la historia musical de Ciudad Juárez.

Ante esta propuesta, es posible también aproximarnos a una categorización de las diferentes actividades que se desarrollaron en esta frontera durante estas épocas. Así ponemos encontrar las siguientes que tienen que ver con el ámbito musical.

- Músicos

- Cantantes (hombres y mujeres)

- Maestros de ceremonia (MC)

- Maestros de canto

- Directores de orquesta

- Orquestas

- Cabarets

- Empresarios

- Locutores de radio

- Periodistas/reporteros de espectáculos 
Leonora Saavedra (2016), entiende este tipo de comunidades como agentes sociales: "cuyo trabajo epistémico y semiótico contribuye a la articulación y circulación del conocimiento público de lo nacional, es decir, como intelectuales en el sentido más amplio". A tal efecto, Saavedra considera a "los compositores, músicos, musicólogos -y también a los empresarios y administradores culturales- como agentes sociales".

En el México de los años 20, hubo visiones encontradas de lo mexicano y lo mexicano moderno que fueron articuladas alrededor de la canción mexicana y del foxtrot por compositores y autores de concierto, teatrales y de música popular, como Manuel M. Ponce, Manuel Esparza Oteo, "Tata Nacho" o Manuel Castro Padilla; así como por miembros de las élites políticas, periodísticas y empresariales. Estas visiones circularon y se negociaron en espacios como teatros, publicaciones periódicas, orfeones, escuelas de arte, festivales públicos y repertorios de música (Saavedra, 2016).

Ya en su momento, en la misma cátedra, pero en 2002, Carlos Montemayor conceptualizó a la música como aquella masa sonora que nos rodea o que nos generamos cotidianamente y la identifica con "ciertos valores sonoros que culturalmente denominamos o aceptamos como música”, para luego preguntarse: ¿Cuándo un sonido es parte del lenguaje? ¿Cuándo, parte de la música?, se cuestiona el autor y deja abierta la discusión sobre el papel que juega la música como agente social (Montemayor, 2002).

\section{UN BREVE RECORRIDO MUSICAL Y SUS DIFERENTES ÉPOCAS}

\section{Periodo romántico}

Este periodo podríamos catalogarlo como romántico por el tipo de música que se tocaba: valses, mazurcas, polkas, entre otras. En general, música catalogada como romántica. Aquí podemos encontrar un trabajo pionero al respecto en la obra recopilada de Raúl Balderrama (2015), que culminó en un disco compacto: Joyas de la Música Chihuahuense producido por Gobierno del Estado de Chihuahua en 2015. En él, Balderrama presenta el trabajo de 
dos de los compositores chihuahuenses más importantes de principios del siglo XX: Arturo Tolentino, coahuilense, avecindado en Ciudad Juárez y Francisco Moure, quien produjo parte de su obra en esta frontera, entre México y Estados Unidos, concretamente entre Ciudad Juárez y El Paso, Texas.

Gracias a Balderrama (2015) se ha recuperado parte de la obra de estos dos grandes compositores, cuya música se escuchó, se tocó y se bailó en el siglo XX. Es en Ciudad Juárez donde escribieron dos de los más famosos valses que se recuerdan en nuestro país: Julia, de don Francisco Moure y Ojos de juventud, de Arturo Tolentino. De acuerdo con Balderrama, es en Juárez donde Tolentino compuso gran parte de su obra hasta su muerte en 1954; de su autoría, Eyes of youth, basado en la película estadounidense, fue creado entre sus viajes y estancias en Parral y Chihuahua capital, al igual que la marcha Parral Unionista y el famoso foxtrot, Alma Parralense. Por su parte, Moure, realiza la mayor parte de su obra tanto en Chihuahua capital como en El Paso, Texas, algo muy frecuente en aquellos años (1920-1930).

En este punto no tiene duda Balderrama (2015), quien en su trabajo afirma que el vals Julia:

[Moure] Lo escribe en Chihuahua, dedicado a Julia Quevedo, taquillera del Teatro Colón en El Paso, Texas. Otras de sus grandes obras, como sus valses Mon Amour, Salvador, Atardecer y el Vals de las Calabazas; su canción Los Besos que te di; el paso doble Santa Rita y la polka San Diego y el danzón de Los Coyotes, los escribió en Chihuahua; mientras que su Calle Siete, una hermosa polka, lo hizo en El Paso [Sic]. Para ver la importancia de estos autores, baste decir que sus principales obras: Julia y Ojos de Juventud fueron grabadas en México, España, Nueva York y Los Ángeles, entre 1921 y 1930. Otro autor importante es Lauro Ortega, autor de Alborada, una canción que fue muy popular por aquellos tiempos (Balderrama, 2015).

\section{Periodo de la Ley Seca y la Guerra}

Esta es la gran época de la música en Ciudad Juárez: la de los grandes espectáculos y las grandes bandas, músicos y cantantes 
del esplendor y la buena vida en la frontera. Son los tiempos en que se aprovecha la implementación de la llamada Ley Seca o Prohibition en los Estados Unidos, que tiene aquí su gran nicho de todo tipo de oportunidades. Es el nacimiento de Juárez como una urbe cosmopolita. Así, comienza la proliferación de los grandes cabarets, de los restaurantes lujosos y por supuesto de la música, mucha música, cantantes, bailarines, del destape total. Esta época se ubica de 1920 hasta los años 70. En este tiempo aparece otra forma de "diversión" en la región que tiene que ver con la sexualización del espectáculo que tiene a la mujer a su principal atractivo:

Los bailes sensuales y privados, streptease, tabledance, tuvieron su auge no solo con los habitantes de Ciudad Juárez, sino también entre camioneros de autobuses foráneos y de carga. A su vez, estas prácticas de servicios sexuales, traspasaron la frontera hacia comunidades de El Paso, Texas y lugares circunvecinos. No se diga de los soldados del Fuerte Bliss [sic]. Se podía apreciar a cientos de soldados estadounidenses embriagados por las calles de Ciudad Juárez, derrochando dólares por doquier. Algunas veces haciendo alarde de su poder adquisitivo, contrataban los servicios adicionales de mariachis y conjuntos norteños (Carmona, 2015).

De esta época data la mayor parte de músicos, cantantes, maestros de ceremonias, empresarios, directores de orquesta y maestros de canto que dieron lustre a la frontera. Resalta aquí la creación de la célebre Banda Infantil Municipal, del maestro José Rodríguez Herrera:

[...] fundada en 1945, con niños de entre 9 y 11 años de edad, principalmente de las escuelas primarias Madero, Juárez, Bellavista y mayoritariamente de la Miguel Ahumada. [...] De esa Banda surgirían grandes músicos como Manny García, Luis Márquez, Lino Rodríguez, Miguel Herrera, Ramón Martínez, Juan Carrillo y Cayetano López Zertuche (Gutiérrez, 2002). 
Cayetano López al paso de los años dirigiría esta mítica banda que se convirtió en los hechos en algo así como la primera escuela de música que se tuvo en la frontera, ante la escasa oferta de planteles, a diferencia de Chihuahua, donde había una interesante oferta. En ese orden, otra institución de aquella época es la Academia Normal de Música de Libertad Montelongo, ubicada en la avenida Juárez y Abraham González, arriba de lo que entonces era la Oficina de Correos (Gutiérrez, 2011). Montelongo era pianista, y junto con su hermana, tocaban en lo que fue el Teatro Libertad. No queda claro si también componían. A decir de Luis Maguregui (2017), quien ha rastreado su obra, ambas lo hacían:

Bueno, me dice una de sus sobrinas, -que todavía vive-, que sí, que sí tienen alguna composición, pero la familia no la ubica. La partitura, por ahí debe estar. Y esto es algo que es muy común. Mira, una cosa que es muy común en este asunto de la música escrita, es que, justamente como es una hoja de papel, o dos, o una hoja vieja de papel que se está deshaciendo de viejo, la gente, a veces, la guarda mal, en un lugar donde no la debe guardar y la hoja termina destruyéndose. (Maguregui, 2017).

Por estos relatos es que conocemos la existencia de esa intensa vida musical. Era inconcebible que uno de aquellos lujosos lugares no tuviera música en vivo, música con grandes bandas. Algunos cálculos indican que a fines de la década de los años 50, en Ciudad Juárez había más de 1800 músicos tocando en diferentes bandas (Gutiérrez, 201) y había experimentado un espectacular aumento de su población. De los 8218 habitantes que se tenían al principio del siglo XX, para esa década, la población se había incrementado en un 150.70 por ciento, llegando a los 122566 habitantes (Chávez y Sánchez, 2010). Algunos reportes indican que durante estas décadas, Ciudad Juárez llegó a recibir hasta 400 mil visitantes al año (Olivas, 2014).

[...] que prácticamente invadían Cabarets [sic], salones de baile, cantinas, casinos, restaurantes, cafeterías, tiendas de artesanías, hoteles 
y todo tipo de centros nocturnos se encontraban apostados sobre la Avenida Juárez, Mariscal, 16 de Septiembre, Segunda de Ugarte, María Martínez, Lerdo así como en callejones y calles aledañas, que daban servicio las 24 horas, la zona no dormía (Olivas, 2014).

\section{Maquila, rock and roll y cumbias}

Este periodo va de los años 60 con la llegada de la industria maquiladora en Ciudad Juárez y se prolonga hasta los 80, aproximadamente. El rock, con Elvis Presley a la cabeza, cobra auge aquí, lo mismo que la cumbia. Maguregui (2017) hace una fuerte crítica al rumbo que tomó la música en esta frontera, respecto a la cumbia, pero en especial a la banda:

[...] es la música de salón, la música que se tocaba en los salones de baile que son los cumbieros. Nosotros los músicos, que no tocábamos cumbia y que tocábamos rock o que tocábamos otra cosa, siempre nos referíamos ellos como los cumbieros, se fue de cumbiero, lo cual quería decir que era alguien que prefirió la música fácil, que son grupos que empezaron a trabajar en algún sitio maquilador, como el Malibú, por ejemplo. Y pues claro, ahí tenían que tocar cumbia. No hay duda alguna de que el boom maquilador va a la par de la cumbia. Definitivamente, incluso yo, erróneamente, llegué a pensar que la maldición más grande que le había pasado a la música latinoamericana, era la cumbia. Y digo erróneamente porque después vino la banda. Y no me imaginé lo que venía (Maguregui, 2017).

Para Maguregui, la cumbia no tiene ningún aporte a la música en la frontera, pero no niega el impacto que tuvo:

Para empezar, la cumbia es una música fácil de tocar, muy fácil. O sea, tocar cumbia no tiene chiste, casi ninguno de los instrumentos que se usan tiene algún grado de dificultad. Es una música muy simple, pero a la vez también es muy de baile. Y de eso se trataba, que fuera fácil de bailar. Entonces, pues todo el mundo tocaba cumbia y cuando digo todo mundo, me refiero no solo a los grupos de 
Juárez, sino en todo México. La cumbia pegó horrores (Maguregui, 2017).

A diferencia de la cumbia, la música norteña tiene una onda raíz en la cultura fronteriza, incluso en cuanto al uso de instrumentos.

[...] La música norteña original es una música tradicional del norte. Tiene todo su origen y desarrollo a partir de los corridos de la Revolución. Pero esta, sí tuvo, digamos, una influencia, en las cantinas, los bares. Era música de cantina, de bares. Habían tomado, por ejemplo, instrumentos como el tololoche, que no es más que un contrabajo pero modificado a tres cuerdas nada más y generalmente construido por ellos mismos, el contrabajo; el acordeón. Le agregaban un saxofón y un bajo sexto, que es una guitarra de doce cuerdas realmente, una guitarra de doce cuerdas que se toca de manera distinta pero que tiene doce cuerdas y es un instrumento grave, es como una guitarra grave. Pero el bajo sexto original si era eso y algunos otros instrumentos que, algunos desaparecieron, como la redova, por ejemplo, un instrumento de percusión. También utilizaban una tarola, porque generalmente no usaban una batería completa sino una tarola. Y todos esos instrumentos, digamos, menudeaban por las cantinas de Juárez (Maguregui, 2017).

Era pues una música marginal, diferente a los grandes movimientos musicales que había en la frontera, donde sus grandes temas evolucionaron con el tiempo hasta llegar a lo que conocemos hoy como narcocorridos.

[...] en un principio pues la figura era el caballo, ¿verdad?, el ser perseguido por las fuerzas del gobierno. ¿El arma? La carabina 30-30 que venía de la Revolución. Y luego, se va transformando el caballo en la troca; la 30-30 en el AK47. Pero siguen los mismos temas, la persecución por parte de la policía, pero nada más que ahora por otras razones, por el trasiego de la droga. La música norteña es transversal a la época (Maguregui, 2017). 
Como grupos de este tipo de música, destacaron en Ciudad Juárez Los Rivereños del Nazas, que luego se transformarían en Los Rivereños de Juárez. También surgió el conjunto Chaveña Brass, inspirados en la célebre Tijuana Brass. La combinación de cumbias y música norteña fue muy común en la época. Cumbias en los salones, música norteña en las cantinas de la avenida Juárez, pero sobre todo de la calle Vicente Guerrero.

En cambio, el rock, ya sin el and roll, cobró gran auge en la frontera. Por su importancia, se reproduce íntegra la parte correspondiente a esta época, de la entrevista realizada al músico e investigador fronterizo Luis Maguregui, donde la letra S corresponde al entrevistador (Servando) y la L al entrevistado (Luis).

S. Y entonces, llega el rock and roll...

L. Sí, el rock and roll. En los 60, a principios de los 60, pues el twist y el rock, empiezan a pegar y comienzan a surgir aquí en Juárez grupos como los Seven Teens de Beto Valtierra, pero también los Night Twisters. Hay una época a principios de los 60 donde existe una buena cantidad de grupos de rock. Te puedo mencionar, además de los Seven Teens y los Night Twisters, a los Little Kings, por ejemplo, o a otro grupo que se llamaba así: Los Starlighters o Los Silver Boys, que son los mismos Silver de ahora... por lo menos dos de ellos son los mismos.

S. Y ya después se transformaron...

L. Ya después se transformaron en solo Los Silver, hicieron una banda más grande continuaron con sus éxitos, hasta hoy en día. Y así, te digo, había muchos grupos más, muchos.

S. ¿Cómo cuáles?

L. Hubo otros grupos. Algunos alcanzaron a grabar en México algún disco, como Los Chijuas, ${ }^{4}$ que tocaban sobre todo en fiestas, digamos de la gente del Teresiano, de los niños bien. Pero bueno, con el tiempo se fueron a México, hicieron una gran temporada, larguísima temporada allá, grabaron algunos discos, con covers, en español y algunos en inglés. Ellos com-

4 El nombre es la unión de Chihuahua y Juárez. 
ponían. Los dos hermanos Ganem componían y en sus discos lograron meter algunas piezas originales. Cosa que no se podía, no era tan fácil en aquellos años para los grupos de rock.

S. Se privilegiaban los covers, ¿no?

L. Sí, se privilegiaban los covers, porque era la manera de vender más discos. Otros grupos eran, por ejemplo, La semilla del amor de Sergio Negrete, que nunca grabó un cover, nunca cantó uno. Él siempre tocó sus propias canciones. Esa era su característica principal y creo que fue un gran mérito. A Sergio le gustaba mucho el show y salían pintados como el grupo Kiss. Pero finalmente es un grupo que tenía su propia identidad y cantaba su propia música. En esa época, Sergio sale de una agrupación que se llamaba La Mafia. También estaban Los Hell Angels originalmente, y luego La Mafia, que es la que da origen al Revolution. A Sergio Negrete ya no le tocó el Revolution, a él le tocó ser el organista de La Mafia. Entonces, en los años 60, a fines de los 60, ya hay muchos grupos de rock y muy buenos, muy buenos algunos. Algunos de los grupos de la anterior década persisten, por ejemplo, todavía están los Night Twisters, que todavía andaban ahí.

S. Y tú, ¿a qué le atribuyes, por ejemplo, este boom de tantas bandas, tantos grupos, tantos músicos?

L. El boom no lo sé. Yo creo que el rock pegó en Juárez y en todas las fronteras como en Tijuana, donde tú sabes que hay un movimiento muy parecido, ayudado por una extraña disposición que había, donde no se podía tocar música en inglés. Esto es lo que hace que empiecen a grabar todo el mundo covers en español. Esto es, las mismas canciones en inglés, pero en su versión en español. Es curioso que no da origen a un rock nacional, como ocurrió en otros lugares, como en Argentina, por ejemplo, donde también hubo la misma prohibición pero ellos empezaron a crear su propia música. En México no, las compañías de discos, que eran las que contrataban a los grupos, les exigían que grabaran los grandes éxitos que se estaban oyendo en Estados Unidos. Si en Estados Unidos estaba pegando Creedence Clearwater Revival, 
aquí la compañía tomaba un grupo y le decía: ustedes van a tener que grabar esta pieza que está pegando allá. Entonces, la mayor parte de los grupos de Distrito Federal hacían eso, los Chijuas de Juárez participaron en ese movimiento. Incluso tuvieron un gran éxito con una pieza que ellos le pusieron El Esquimal, que se llamaba The Maghty Quinn y era una pieza de Bob Dylan, pero ellos grabaron la versión de un grupo inglés que se llamaba Manfred Mann e hicieron la versión de Quinn The Eskimo o The Maghty Quinn y le pusieron El Esquimal y tuvieron un gran éxito. Inclusive esa pieza, fue tanto su éxito que la grabaron en inglés y en español. Si tú comprabas el LP de los Chijuas, venía esa canción en inglés por un lado y en español por el otro.

S. ¿De 45 revoluciones o en LP?

L. No, no, LP, ya con muchas otras piezas. Y bueno, la mayor parte de los grupos mexicanos así era. Los de aquí de Juárez que lograron perfilarse, ir a la televisión mexicana y todo eso pues fueron como ya te dije, Los Chijuas. El grupo de Beto Valtierra una década antes, Los Seven Teens, que también participaron en programas de televisión allá y tuvieron un gran éxito y grabaron varios discos para la marca Musart. Pero bueno, como te digo, lamentablemente grababan covers, no podemos hablar propiamente de un movimiento.

S. O sea, ¿no se puede hablar de un movimiento, de un rock fronterizo, propio de Juárez?

L. Fronterizo, no. Porque eran casos aislados, como el de Sergio Negrete y de algunos otros grupos así, que llegaron a componer una pieza.

$\mathrm{S}$. Ni lo mismo en la época anterior.

L. No. En la época anterior era lo mismo. Tú te metías a un bar y oías la música de Glenn Miller, escuchabas Patrulla Americana, Serenata a la luz de la luna, cosas así. O bien, los boleros, los grandes boleros que tocaba Marco Antonio Muñiz y esa gente. O los tangos, pero no escuchabas música original. No, no.

S. Y este movimiento de rock sería encabezado por... 
L. Los Seven Teens, que son de principios de los 70, por ahí.

S. O sea, digamos, ellos fueron los pioneros.

L. Sí, son pioneros. Ellos son pioneros del rock de Juárez. En uno de sus discos, un disco que todavía se consigue hasta la fecha, lo puedes comprar en Sounds, ${ }^{5}$ todavía existe un disco con una portada rara que no tiene nada que ver, pero se sigue reimprimiendo. Ahí aparecen varias composiciones, dos o tres composiciones de Beto Valtierra. La Panchita, por ejemplo, que es una composición, que es un extraordinario solo de sax. Es una pieza para sax; el Twist de los Gorrones, por ejemplo, así le llamaba y es una composición de ellos. Sí claro, otras piezas conocidas como Blueberry Hill, o sea, Colina azul, incluso una pieza que realmente era un clásico de jazz, El hombre del brazo de oro. Ellos, intentaron meter algunas de sus propias composiciones, particularmente Beto, pero no fue fácil.

S. En ese sentido, Beto Valtierra es un pionero del rock en la frontera, ¿no?

L. Sí. Yo pienso que sí. Beto Valtierra es un músico muy poco valorado. Pero él tuvo, tiene una larga trayectoria. Porque después de esos legendarios Seven Teens, que era un extraordinario grupo de rock, él forma en México otros Seven Teens, que ya no eran siete, eran más; porque él se va al Distrito Federal y allá se ocupa de acompañar a grandes artistas y tienen un trabajo muy serio allá. Igual la orquesta de su padre, Don Cuco, le pasa lo mismo, se va a México, forma una orquesta, que viene siendo la orquesta de Cuco Valtierra, y pues tienen toda una época allá. Igual le sucede a Roy Ramos. Todos esos músicos, salieron de aquí. Es curioso fijate, cómo los músicos de Juárez eran como la base para las estrellas del Distrito Federal, los de Juárez y los de Tijuana.

S. Grupos que se formaron allá en el entonces Distrito Federal, pero con orígenes aquí, en Juárez.

5 Establecimiento local de venta de música, instrumentos musicales y aparatos electrónicos. 
L. Los grupos se formaron allá en el DF, sí, así fue. Pero en Tijuana pasa una cosa más o menos parecida con Javier Bátiz, que es de Tijuana, por ejemplo.

S. Y, ¿por qué pasaba eso, Luis?

L. ¿Por qué pasaba? Bueno, porque en México no sé, los discos importados de músicos de rock eran muy caros, muy pocos los tenían, y aquí no. Aquí los podíamos conseguir muy fácilmente, por ser frontera se conseguían más rápido. Vamos, el nuevo disco de Los Beatles, por ejemplo, pues allá salía seis meses después de aquí. Y los músicos de Tijuana, pues era lo mismo, o sea, ellos se iban al D.F., pero de Tijuana les mandaban los discos y ponían las piezas de Los Beatles. Yo recuerdo, fijate, la canción esa, aquella de Penny Lane o Strawberry Fields Forever y algunas de esas canciones de Los Beatles de esa época, acababan de salir, tenían muy poco tiempo que había salido el disco y ya había un grupo de Tijuana que estaba en el D.F., que se llamaba Los Five Fingers que ya la estaban tocando y bien.

S. ¿Y cómo, la tocaban de oídas o conseguían las partituras?

L. Sí, ¡de oído! Esos músicos eran de oído. Entonces, decías tú, ¿pero si acaba de salir, ¿cómo le hacen? Y es que eran muy buenos. Por ejemplo, recuerdo a unos músicos de Durango, los Dug Dug's se llamaban. Que también Dug Dug era porque eran de Durango, que igual, era impresionante como se fusilaban las piezas, las copiaban, casi idénticas. Entonces, decías tú, ¡no es posible! ¡Se oye igualito!, por lo menos a mí me parecía que se oían igual y creo que sí, así era. Y eran músicos del norte, muy muy, muy competentes. Lo mismo aquellos Chijuas y bueno, en fin. Muchos de esos músicos de la frontera, intentaron grabar su propia música en algún momento; los Dug Dug's, por ejemplo, los Chijuas también, de Juárez, pero yo creo que el movimiento musical norteamericano fue tan aplastante...

S. Que los ahogó...

L. Que ahogó a todas las manifestaciones pequeñas de la provincia mexicana, digamos. A raíz del Festival de Woodstock 
y de todo ese movimiento que fue, realmente mundial y muy aplastante, pues no hubo posibilidades de que surgieran, digamos, más músicos mexicanos.

S. Y en la frontera.

L. Sí. Y te estoy hablando no solamente de México, de Juárez, de México, de Tijuana, De todo el mundo. Son muy pocos los grupos que son de otra nacionalidad, que no sean ingleses o americanos, ${ }^{6}$ que lograron algún lugar. Son muy raros, como Los Bravos que eran españoles y que cantaban aquella canción Black is Black. Ellos eran españoles y tuvieron éxito con dos o tres piezas en inglés, que grabaron en inglés y les pegaron.

S. Sí, pues eran parte de la nueva cultura de la naciente modernidad.

L. Claro y en Juárez no era la excepción. Habían grupos muy competentes, como Los Night Twisters, por ejemplo, y en su momento, era impresionante escuchar el nivel de virtuosismo para tocar las piezas americanas.

En estos grupos hay que agregar también a Los Frontera, Los Juárez 4, Los Griegos, y por supuesto don Carlos Aceves, entre otros muchos más.

\section{La liberación... y el latinoamericanismo}

Es el auge de la cultura estadounidense que impone su música, su cine, pero sobre todo, una nueva forma de consumo cultural. Es la década de los 70 y que se prolonga hasta principios de los 90. Es la de la música disco, de las modernas discotecas y un nuevo estilo de baile que cautivó a todo el mundo. Pero al mismo tiempo, surgió una especie de contracultura, una respuesta a ese avasallante estilo norteamericano y se decide voltear al sur: la música latinoamericana. Y por supuesto, la época del nacimiento de la más rutilante de las figuras de la frontera: Juan Gabriel, que es un tema aparte.

S. Y luego, ¿qué viene?, musicalmente hablando...

$6 \quad$ Se refiere a norteamericanos. 
L. Yo creo que lo que sigue es el furor de la música latinoamericana, en los músicos de Juárez y entonces empiezan a surgir nuevos grupos.

S. En los 70.

L. Sí, en los 70. Surgen grupos de música latinoamericana que ya no tocan. Digamos que de alguna manera, menosprecian el rock. Ellos tocan en español, usan guitarras acústicas y ya sus ídolos no son los grupos de rock sino grupos como Mocedades o grupos latinoamericanos como Los Calchakis o Los Folkloristas. Aprenden a tocar instrumentos andinos, como el charango, la quena y cosas así y tocan música latinoamericana.

S. ¿Y qué grupos son lo que ubicas en esa época?

L. Algunos todavía existen como Libertad América. También son de esta época el Grupo Romerías, el Cuarteto Universitario, que todavía existe con otros integrantes. Había otros grupos, como uno que se llamó Songuirongui, el grupo Estival, El Silencio, en donde yo estaba. Nosotros no tocábamos con instrumentos latinoamericanos realmente, tocábamos con instrumentos modernos. Por ejemplo, teníamos piano eléctrico, bajo, batería, usábamos guitarras acústicas, hacíamos voces y cosas así pero nunca nos llamó la atención imitar la música latinoamericana. Tocábamos música de Silvio Rodríguez y de Pablo Milanés y de todo eso, porque también ese es otro de los grandes detonantes, como la nueva trova.

S. La nueva trova...

L. Claro, entonces, nosotros nos fuimos por ese lado más bien, mientras que otros grupos imitaban a Los Calchakis, o a Los Incas, o a otros grupos, nosotros no.

S. O a Los Folkloristas.

L. Sí. Y eran como, como, digamos, había un menosprecio al uso de esos instrumentos. No se veía bien que usáramos instrumentos eléctricos. Entonces, nosotros estábamos en medio.

S. Era como una contracultura, ¿no?

L. Sí, era una contracultura y nos veían mal porque teníamos un sintetizador electrónico, jimagínate!

S. Era una herejía... 
L. Era una herejía. Una vez tocamos una versión electrónica, no electrónica sino más bien de heavy metal, del ¡Cóndor Pasa! y casi, casi nos excomulgan. Solo porque nos atrevimos a tocar al Cóndor Pasa con acordes de heavy metal. Sucede que se nos hizo interesante hacerlo porque se podía y ya. Y aquello fue, en un... fijate, hubo una sucesión de músicos latinoamericanos que se llamó Movimiento por el Canto Latinoamericano y éramos varios grupos que cultivábamos la música latinoamericana, entre ellos, nosotros, que pues éramos los más herejes, ¿cierto? Pero hubo ese movimiento y hacíamos un festival cada año.

S. ¿Y dónde lo hacían?

L. En la sala de lo que hoy es el Centro Cultural de la Ciudad, la sala del INBA, como se le conocía, ahí. Y ahí fue donde tocamos el Concord Pasa, porque así le pusimos. Pero te digo, el lugar se llenaba, era bastante la audiencia que había para ese tipo de música.

S. ¿Estamos hablando de qué época?

L. Fines de los 70 y principios de los 80, básicamente. El grupo Silencio, tocó entre el 74 y el 82, por ahí.

S. ¿Ahí entran también los de Ruid2?

L. Sí, claro. De hecho, Roberto Torres, él tocaba con el cuarteto, su hermano Fernando que murió recientemente, tocaba con el grupo Estival y ellos que eran como el cuarteto también tocaban ese tipo de música. Aunque ellos no cultivaban la música romántica, más bien tocaban música latinoamericana y ahí tocaba el bajo Luis Carbajal y que hoy forma parte del cuarteto actual. El grupo Estival, fue así un pilar de ese movimiento. Ellos, tanto Roberto cuando se sale del cuarteto, como su hermano Fernando, forman Ruidos, Sonidos y Otras Yerbas, de gran tradición en la UACJ.

S. ¿Otros...?

L. Por supuesto que está el grupo Amanecer. Ellos en principio tocaban acústico y tocaban canciones de Mocedades también; pero fueron evolucionando a tocar música de Led Zeppelin y hasta de Queen, que es bastante difícil de tocar, sin 
embargo, ellos lo hacen muy bien porque son músicos muy competentes. Este grupo también tiene una larga trayectoria desde sus orígenes. Principios de los 80 hasta la época actual que todavía se presentan y han grabado también su propia música y bueno, es un grupo por separado, digamos, que se cuece aparte, por otro lado.

\section{La ola fronteriza}

Llegamos a la época actual, la de la violencia, la del resurgimiento, la de los grandes movimientos musicales que van desde la proliferación de música clásica por medio de diferentes orquestas sinfónicas que surgen en Ciudad Juárez, hasta grupos de hip-hop, rap, del llamado tecno-rock y otro tipo de variantes. Son los tiempos de la música de banda.

Así, el periodo va del 2000 a la fecha. En ese tiempo la Universidad Autónoma de Ciudad Juárez consolida su Orquesta Sinfónica, a cargo del maestro Carlos García Ruiz en su primera etapa y luego a cargo del maestro Guillermo Quezada. ${ }^{7}$ Se consolida su Orquesta Sinfónica Juvenil y su carrera de Música, de donde surgen los músicos que no solo tocarán ahí sino en diversos grupos. Impulsa un ambicioso programa de ópera que le da fama a nivel nacional con su Festival de Ópera en el Desierto, que se realiza en mayo. Así también surge la Orquesta Esperanza Azteca del Grupo Salinas y un sinnúmero de agrupaciones. Las escuelas particulares quieren tener sus propias sinfónicas como El Colegio Bilbao. Antes, aparecía una orquesta que tiene como propósito promover la paz y trabajar en las zonas difíciles de la frontera. Así surgió la Orquesta Ccompaz, a cargo de la organización Ciudadanos Comprometidos con la Paz, un organismo de la sociedad civil que nace para contrarrestar la ola de la violencia y la falta de seguridad pública que aquejaron a Ciudad Juárez durante la administración del presidente Felipe Calderón y su "guerra contra el narcotráfico". La organización busca desincentivar el uso de cualquier tipo de

7 La Orquesta Sinfónica de la UACJ profesional desapareció en 2018. Actualmente se impulsa a la Orquesta Juvenil. 
arma y reconstruir el tejido social, por medio del arte y la cultura en zonas precarias de la ciudad. ${ }^{8}$

En esta época, la música se asume como una forma de combatir la cultura de la muerte y la industrialización.

[...] Ese sábado 16 de marzo un movimiento musical naciente en Ciudad Juárez estaba resistiendo a la "cultura de la muerte y la industrialización”. La Nueva Ola Fronteriza, como lo han bautizado sus creadores, es el más reciente esfuerzo por rescatar el tejido social en Ciudad Juárez mediante la música. El colectivo formado por tres músicos y productores, está luchando junto a otros, por crear espacios que seduzcan más a los jóvenes que las drogas, el sicariato y el narcotráfico (Chaparro, 2013).

Se trata de Pájaro Sin Alas, Rodolfo Ramos Castro, un estudiante de psicología de 20 años de edad de la UACJ, quien encabeza este movimiento llamado la Nueva Ola Fronteriza, a la que define como psicodelia sin límites. El término viene de la música popular de los 60, con sus teclados psicodélicos, sus letras pop mezclas con ritmos de cumbia, de reggaetón y de maracas.

Queremos hacer saber que como fronterizos no nos identificamos plenamente con lo mexicano, pero tampoco con lo gringo. Aquí todos se influencian por la música europea o norteamericana, pero esos no somos nosotros, explica Rodolfo. El colectivo está formado por Airek, Flower Drive y Pájaro Sin Alas, tres ex miembros [sic] de una banda de rock llamada Purple Haze, aludiendo a la música de Jimmy Hendrix. A pesar de que cada proyecto es distinto entre sí, conservan una misma línea: los teclados y sintetizadores psicodélicos (Chaparro, 2013).

Pero también aparecen otros grupos, con diferentes propuestas musicales como Golem, con una mezcla de rock inédito que sigue asombrando en medio de una escena local dominada por los covers de todo género. Lo que hace distinto a Golem es su

8 Actualmente esta organización se encuentra sin mucha actividad, derivado de cambios en su organización interna. Para conocer más sobre la misma se recomienda visutar su página: http://ccompaz.org/ 
ejercicio anudado a las influencias musicales, muy variadas, de sus integrantes. El grupo encabeza una corriente musical que gusta a muchos jóvenes en la frontera. Su música es una mezcla curiosa que definen así:

Las canciones que empezamos a componer eran medio electrónicas, medio progre, medio jazz, medio rock. Podía parecerse a todo eso, no lo sabíamos, pero de lo que sí estábamos seguros era que no nos estábamos casando con nada. Golem es una banda muy pasional, entreverada de hard rock, una corriente musical heredera del rock and roll, surgida en Europa y Estados Unidos, en los años sesenta, y cuyos grupos más representativos fueron Deep Purple, Black Sabbath y Led Zeppelin. Golem reconoce a por lo menos siete voces de las que ha abrevado: King Crimson, Beach House, Can, Steven Wilson, Mike Patton, Chet Faker. [...] Desde muy temprano han estado vinculados, al hard rock, el heavy metal, al jazz y al blues, ritmos con carta de ciudadanía en estas tierras desde que las primeras notas que llegaron del norte fueron las de Stairway to Heaven, esa conspiración tersa escrita contra la tirantez del silencio (Martínez, 2014).

Integrada por Yuriav Montañez, Omar Rosas, Isaac Galarza, Clara Gallardo y Roberto Ortega, este grupo emprendió el reto de crear un ritmo muy local, pero a la vez muy forastero, en referencia clara a la composición híbrida de Ciudad Juárez.

Otro movimiento que cobró gran importancia en la frontera en los momentos álgidos de la llamada Guerra contra el narcotráfico fue el hip-hop que tuvo gran repercusión, particularmente en los barrios marginales de la frontera. Y aunque es siempre fue una corriente ligada siempre a los varones, aquí en Ciudad Juárez, las mujeres cobraron gran relevancia por medio de este movimiento considerado por la literatura especializada como de resistencia. Batallones femeninos es una agrupación de hip-hop de Ciudad Juárez que nace en 2009. Está conformada por mujeres jóvenes estudiantes, artistas, madres solteras, trabajadoras, amas de casa, con trayectorias previas en grupos mixtos de hip-hop. 
Tienen en común la pasión por la música y el deseo de manifestar las más sentidas problemáticas que viven en una escena musical predominantemente masculina. Aunque habían escuchado hablar unas de otras y en algunos casos se conocían por su participación en eventos de hip-hop a los que asistían con sus propios grupos, no habían tenido contacto directo entre ellas. [...] Desde entonces, cuentan con un amplio repertorio mediante el cual transmiten la realidad de la ciudad, la frontera, la violencia, la migración, la participación de las mujeres en el hip-hop, los abusos policiales y el feminicidio, entre otros temas. Si bien han hecho una importante crítica al machismo en el rap, no se oponen a la colaboración con los hombres de la escena, pues todas provienen de grupos mixtos y mantienen la vinculación con ellos (Silva, 2017).

Con una larga tradición en Ciudad Juárez, también el jazz tiene su lugar en la frontera. Actualmente, destaca el juarense Gerry López, quien es considerado uno de los músicos jóvenes más prometedores en la escena del jazz internacional. En este rubro existe una pléyade de jóvenes músicos en la frontera como Karlo, Abel y Álvaro Mireles. Y con toda una tradición en Ciudad Juárez, el maestro y formador de innumerables generaciones de hoy estupendos jazzistas, Fortunato Pérez. Sin faltar, uno de los grandes del jazz mexicano: el gran Tino Contreras. Como impulsores destacan el Alfonso "Pato" Quiñones con el Juárez Jazz Fest; actualmente la Universidad Autónoma de Ciudad Juárez se cuenta como un fuerte apoyo, así como Gobierno del Estado con el ya tradicional Festival de Jazz.

No se pretende agotar aquí una lista y sin duda que habrá omisiones, pero en diferentes corrientes y movimientos también destacan otros músicos como el guitarrista Aquiles Valdez (OEPD) y el pianista Jorge Vargas, al igual que los compositores Carlos Benítez y Domingo Rodríguez Salomé, este último docente de la Licenciatura en Música de la UACJ, al igual que el maestro Vargas.

Aunque incipientes, hay esfuerzos por rescatar un poco de la historia de la música en Ciudad Juárez. Actualmente existe una 
página de Facebook que se encarga de ello, por medio de la creación de un grupo llamado justamente Historia Musical de Ciudad Juárez. ${ }^{9}$ Aunque caótico, por la dinámica misma de este tipo de redes sociales, finalmente se trata de un intento desde la ciudadanía por reconstruir nuestra historia musical.

\section{EL FENÓMENO JUAN GABRIEL}

Mención especial merece ese fenómeno musical que fue Alberto Aguilera Valadez, mejor conocido como Juan Gabriel de quien hay una abundante e inmensa bibliografía, estudios, reportajes y hoy en día, prácticamente se conoce todo de él, así como del ya mítico Noa Noa, lugar donde iniciaría su historia. No es motivo de este breve recuento abundar en este gran cantante, compositor y figura nacional, la más grande sin duda que ha dado Ciudad Juárez, que como muchos otros que emigraron a estas tierras, aunque no nació en esta frontera, se convirtió en su fiel representante, un ícono identitario de esta zona.

Nacido el 7 de enero de 1950, en Parácuaro, Michoacán, la familia de Juan Gabriel emigró a Ciudad Juárez y fue en la década de los 70 cuando inició el despegue de lo que sería una brillante carrera, con su ya célebre canción No tengo dinero, contenida en su disco El alma joven, que incluía diez canciones de su autoría y arreglos de Chucho Ferrer, Pocho Pérez y Eduardo Magallanes. A Juan Gabriel, en su faceta anterior, como Adán Luna, le tocó cantar en el no menos célebre Malibú. Cantó en prácticamente todos los lugares más importantes de México, incluidos el Palacio de Bellas Artes y el Auditorio Nacional. Sus canciones han sido traducidas e interpretadas en varios idiomas, incluidos el inglés, turco, japonés, alemán, griego, francés y portugués. La Sinfónica de Londres lo grabó, así como las principales orquestas del mundo. Prácticamente no hubo cantante importante, hombre o mujer que no grabara alguno de sus temas.

9 Puede ser consultada en la siguiente dirección: https://www.facebook.com/HistoriaMusical-De-Ciudad-Juarez-377878502251517/ 
Para algunos intelectuales como el fallecido Carlos Monsiváis (2003), Juan Gabriel era una especie de mezcla que recogía la herencia de José Alfredo Jiménez y a tradición de la música norteña, que lo lleva a producir en serie, polkas, redovas, rancheras y que por supuesto, tiene una gran influencia en el tradicional mariachi mexicano. En Ciudad Juárez, fundó la escuela de música Semjase, para niños huérfanos y abandonados. Juan Gabriel, tras una exitosa carrera que se llega a prolongar durante casi 40 años, muere en su departamento de Santa Mónica, California el 28 de agosto de 2016. Es considerado el principal representante de la música regional mexicana de los últimos años con más de 100 millones de discos vendidos. El caso de Juan Gabriel y la importancia e impacto en la historia de la música en Ciudad Juárez, rebasan los alcances de este trabajo, pues por sí solo, es un fenómeno mundial. $^{10}$

\section{REFLEXIONES FINALES}

Al hacer esta breve pasaje de la historia de la música en Ciudad Juárez, una de las primeras conclusiones a las que se puede llegar es que hace falta hacer más investigación y tratar de ordenar toda esa documentación que se encuentra dispersa en estos momentos, desde documentos, fotografías, discos, partituras e instrumentos. Ahondar y hurgar mucho en los archivos: tanto en los oficiales, como en los particulares, descubrirlos, buscar trabajarlos, encontrar a los autores, a los compositores, para de esta manera poder rescatar sus obras. En ese sentido, el Programa de Licenciatura en Música, tiene ante sí un gran reto en materia de investigación musical por medio de sus maestros de tiempo completo. Integrar un archivo, un centro de documentación y análisis de la música en nuestra frontera.

Está pendiente aún el rescate de los grandes compositores, de los grandes músicos y de los grandes artistas juarenses. Cier-

10 Es el mismo caso de otro gran ícono de la frontera Germán Valdez Tin Tan, con su peculiar estilo pachuco. Por sí mismo este tema amerita un tratamiento independiente, pero debido al espacio de que se dispone, se propone para ser abordado en un texto posterior. 
tamente no será una tarea fácil, pero habrá que empezarla, de lo contrario muchas de esas obras se perderán irremediablemente por el paso del tiempo, como lo indica el investigador y músico, Luis Maguregui, en la entrevista realizada para este texto, quien destaca que existen decenas de archivos de compositores juarenses en manos de sus familiares, quienes ni siquiera saben el tesoro que tienen, musicalmente hablando, muchos de ellos guardados en cajas de cartón, con gran peligro de que puedan destruirse, sin que los herederos lo sepan. Hace falta localizarlos, convencer a los familiares que esos documentos tendrán un buen manejo y destino y qué mejor que sea una institución como la Universidad Autónoma de Ciudad Juárez, por medio de su Licenciatura en Música, que lo haga.

Es parte pues, del rescate de nuestro patrimonio musical. Es parte de nuestra historia, de nuestro pasado. Es parte de saber quiénes somos. De nuestra construcción, de nuestra identidad. No vamos a saber quiénes somos si no sabemos quiénes fuimos.

\section{REFERENCIAS}

Castañeda, J. (1996). Estrellas de la Noche. México: UACJ. Fondo para la Modernización de la Educación Superior, Programa de Investigación para la Extensión, Vinculación y Cultura. Citado por L. Sandoval y L. Peña en Historia del cabaret y vida nocturna como transformadores de la identidad cultural en el centro de Ciudad Juárez, Chihuahua, México.

Balderrama, R. (2015). Joyas de la música chihuahuense. Arturo Tolentino y Francisco Moure. Chihuahua: Secretaría de Cultura. Programa de Apoyo a las Culturas Municipales y Comunitarias. PACMYC.

Chávez, J. y Sánchez, É. (2010). El crecimiento urbano de Ciudad Juárez. Una lectura de la cartografía histórica, en Anna Vincenza Nufrio. Ciudad Juárez. La historia de una ciudad y de una frontera. Edición de autor.

Gutiérrez de Alba, E. (2002). Tívoli. Bailando con la historia. Chihuahua: Ediciones del Azar. 
Gutiérrez de Alba, E. (2011). La Fiesta. Recuerdos de una alegre y luminosa Ciudad Juárez del siglo XX. Chihuahua: Universidad Autónoma de Ciudad Juárez.

Maycotte, E. y Moreno R. L. (2010). Entre el temor y la inseguridad, la creación de una zona de silencio en la actividad turística de Ciudad Juárez. México: Revista de Arquitectura, Urbanismo y Ciencias Sociales.

Monsiváis, C.(2003). Escenas de pudor y liviandad. México: Debolsillo.

Olivas, J. de D. (2014). Calles del centro, alguna vez brillaron... con su vida nocturna. El Diario de Juárez.

Rayos, G. (2014). La Heroica Ciudad Juárez, cuatro elementos identitarios: La frontera, la maquila, los centros o plazas comerciales y lo norteño. Cuernavaca.

Sandoval, L. y Peña, L. (s/f). Historia del cabaret y vida nocturna como transformadores de la identidad cultural en el centro de Ciudad Juárez, Chihuahua, México. Chihuahua: Benemérita Universidad Autónoma de Puebla-RN.

Saavedra, L. (2016). La música mexicana de 1910 a 1930. Conocimiento social y comunidad identitaria. Cátedra "Jesús C. Romero. 2016". Centro Nacional de Investigación, Documentación e Información Musical "Carlos Chávez", del Instituto Nacional de Bellas Artes de México.

Silva, D. A. (2017). Somos las vivas de Juárez: hip-hop femenino en Ciudad Juárez. México. Revista Mexicana de Sociología, vol. 79, número 1, enero-marzo.

Referencias internet

Carmona, J. M. (2015). Ciudad Juárez, paraíso de la prostitución. Wall Street International. Revista digital, sección economía y política. 10 de agosto de 2015. https://wsimag.com/es/economia-y-politica/14575-ciudad-juarez-paraiso-de-la-prostitucion

Chaparro, L. (2013). La música en Ciudad Juárez: Combatiendo la cultura de la muerte. https://www.vice.com/es_mx/ article/5g8v4k/la-musica-en-ciudad-juarez-combatiendo-la-cultura-de-la-muerte 
Ccompaz (s/f). "Fomentando una cultura de paz". http://ccompaz. org/ [página fuera de servicio, consultada el 29 de noviembre de 2017].

Martínez, J. C. (2014, 25 de septiembre). Golem. La música que despierta en el desierto de Ciudad Juárez. Fronterad [revista digital]. https://www.fronterad.com/golem-la-musica-que-despierta-en-el-desierto-de-ciudad-juarez/

Olivas, J. de D. (2014, 25 de enero). Calles del centro alguna vez brillaron... con su vida nocturna. El Diario. http://diario.mx/ Local/2014-01-25_d24c73ed/calles-del-centro-alguna-vez-brillaron-con-su-vida-nocturna/.

Silva, D. A. (2017, enero-marzo). "Somos las vivas de Juárez": hiphop femenino en Ciudad Juárez. Revista Mexicana de Sociología, 79(1). http://www.scielo.org.mx/scielo.php?pid=S018825032017000100147\&.script=sci_arttext\&tlng=pt\#B35

Torres, C. (s/f). Historia Musical de Ciudad Juárez [página de Facebook]. https://www.facebook.com/Historia-Musical-DeCiudad-Juarez-377878502251517/

Universidad Autónoma de Ciudad Juárez (2017, 3 de febrero). Himno Universitario con la Orquesta Sinfónica de la UACJ [video]. http://www.uacj.mx/comunicacion/Paginas/HimnoUniversitario.aspx

\section{Entrevista}

Maguregui, Luis. Entrevista personal realizada el 28 de noviembre de 2017. 